\title{
METODOLOGIA ATIVA: A UTILIZAÇÃO DO LÚDICO NA EDUCAÇÃO SUPERIOR EAD
}

CURITIBA/PR JUNHO/2018

\author{
IVANA MARIA SAES BUSATO - Uninter - ivana.bu@uninter.com \\ IZABELLE CRISTINA GARCIA RODRIGUES - Uninter - izabelle.r@uninter.com \\ IVANA DE FRANÇA GARCIA - Uninter - ivana.g@uninter.com \\ VERA LUCIA PEREIRA DOS SANTOS - Uninter - vera.s@uninter.com \\ JOÃO LUIZ COELHO RIBAS - Uninter - joao.r@uninter.com
}

\author{
Tipo: Relato de Experiência Inovadora (EI) \\ Categoria: Métodos e Tecnologias \\ Setor Educacional: EDUCAÇÃO SUPERIOR
}

\begin{abstract}
RESUMO
Atividades educacionais lúdicas são comuns nas séries iniciais, pelo fato de atuarem com crianças, porém, devido a nova caracterização ludificada da sociedade essas atividades estão sendo inseridas também nas salas de aula do Ensino superior. As brincadeiras são elementos que despertam a atenção e curiosidade. Por meio delas é possível se perceber em várias situações de um mesmo contexto, isso possibilita a expansão do ponto de vista. Devido a isso, o presente estudo, faz um relato de experiência, tendo como objetivo verificar se os alunos de graduação da área da saúde, que estudam na modalidade a distância, estão afinados com esse movimento de sociedade ludificada. Para isso, foi disponibilizado jogo on line, estilo tabuleiro, aos 332 alunos no curso de superior de tecnologia, numa unidade curricular, de determinada instituição de ensino superior localizada no Município de Curitiba, Paraná. Por fim os resultados demonstraram que apenas $25 \%$ acessaram a atividade, sendo que entre esses apenas $24 \%$, o número de jogos concluídos (21) em relação ao número total de alunos na oferta (332) percebe-se que apenas $6 \%$ dos alunos realizaram a atividade integralmente. Conclui-se que foi baixa a participação dos alunos com o jogo, e não se sentiram suficientemente atraídos a realizar a atividade proposta.
\end{abstract}

Palavras-chave: Educação Superior. Lúdico. Jogos

\section{AGRADECIMENTOS}




\section{INTRODUÇÃO}

As brincadeiras, por vezes, trazem à tona uma memória afetiva que pode facilitar a compreensão do aluno à determinados assuntos. Por meio das brincadeiras dirigidas é possível que o aluno se perceba em situações adversas, ampliando seu ponto de vista (SCARIN, 2016).

$\mathrm{Na}$ educação é preciso que velhos paradigmas sejam cotidianamente quebrados para que a atenção do discente seja atraída. Assim, faz-se necessário que novos métodos e atividades sejam elaborados e inseridos no contexto educacional, pois conforme afirma Scarin (2016, p. 634) "os brincares (e seus desdobramentos) podem frutificar o ano todo".

Os recursos didáticos de apoio mostram-se eficientes no processo ensinoaprendizagem, portanto, não devem ser vistos apenas como coadjuvantes, mas sim como ferramentas que conduzam à reflexão. Além disso, há que se considerar que "lugares pedagógicos são aqueles onde o poder se organiza e se exercita", como os jogos (ALCÂNTARA; BEZERRA, 2016 APUD STEINBERG, 1997).

\footnotetext{
Segundo Cruz Junior (2017) estamos vivenciando uma sociedade ludificada, onde:Os jogos digitais estão entre as principais formas de expressão e entretenimento da contemporaneidade. Devido à sua popularidade entre crianças, jovens e adultos, esse fenômeno tem recebido crescente atenção em diferentes âmbitos. Nesse sentido, um dos principais interesses sobre os games da atualidade está expresso nas tentativas de transpor o seu poder de "atração e diversão" aos demais segmentos que constituem a vida cotidiana (Cruz Junior, 2017, p. 227).
}

Diante disso, o presente estudo tem como objetivo verificar se os alunos de graduação da área da saúde, que estudam na modalidade a distância, estão afinados com esse movimento de sociedade ludificada.

\section{Metodologia}

Como metodologia utilizou-se o relato de experiência, realizado por meio da disponibilização de um jogo on line, estilo tabuleiro, à 332 alunos da modalidade a distância do Curso Superior de Tecnologia de Gestão em Saúde Pública, referente a uma unidade curricular, de uma determinada instituição de Ensino Superior, cuja sede está localizada no Município de Curitiba, Paraná. Esse jogo foi produzido pelos professores responsáveis pelo curso em parceria com o setor de Tecnologia da referida IES.

A forma de jogar consistia no aluno sair da condição de "Gestor Júnior" e chegar a "Gestor Pleno". Para isso ele deveria lançar os dados virtuais, encaminhar seu "peão" 
até a casa correspondente e responder corretamente as perguntas realizadas para avançar no jogo, até chegar ao fim. O jogo foi estruturado para um embate entre o aluno e o computador e esse seguia o mesmo tramite do aluno (jogar os dados e responder as perguntas).

Os questionamentos disponibilizados no jogo foram elaborados especificamente para essa atividade e utilizou como base o material de aula disponibilizado aos alunos, priorizando os pontos principais da unidade curricular de Gestão em Recursos Humanos.

O jogo não tinha caráter obrigatório, assim, apenas os alunos que tinham interesse é que acessaram e realizaram essa atividade. Contudo, os tutores envolvidos no projeto encaminharam avisos aos alunos explicando os benefícios de participar de tal atividade, como o de exercitar o conhecimento e a auto avaliação. A atividade ficou disponível para realização no período de 26/03 a 07/04/208.

\section{FUNDAMENTAÇÃO TEÓRICA}

Por meio da tecnologia o ensino a distância busca a proximidade do aluno com os professores e o ambiente institucional, por isso, o uso da tecnologia na vida do acadêmico de EAD é fortemente estimulado e a cada momento as instituições buscam novas formas de interatividade com o seu discente (CHRISTO, et al, 2016). Como corrobora Silva (2014, p. 3)

\footnotetext{
A sociedade mudou e a escola não pode ficar à parte. Com a internet e a democratização da disseminação da informação e do conhecimento, as relações de hierarquia entre o(a) professor(a) e alunos foram abaladas, pois $o$ primeiro perde o seu status de ser o transmissor e única fonte de conhecimento para o segundo. $O$ desafio educacional deste século é, sem dúvida, rever as práticas pedagógicas de modo a dar conta das novas demandas do mundo globalizado e do novo perfil de aluno que surge: o do "nativo digital"
}

Para Audi (2014) é inviável manter em formatos tradicionais "na medida em que mais e mais pessoas aderem à nova cultura digital". E tratando-se novas tecnologias, geralmente, atribui-se somente ao uso de smartphones e notebooks, porém, os jogos são componentes tecnológicos de destaque, pois, atualmente, são vistos como uma das principais formas de interatividade dos jovens, e isso denota-se um nicho a ser explorado pelas instituições de ensino. Os jogos permitem que os alunos busquem sozinhos saídas para os desafios encontrados, ou seja, de forma lúdica é possível simular situações práticas do cotidiano de um profissional (SILVA, 2014; FERREIRA ET $A L, 2017)$. 
O dicionário Aurélio (2016) cita que o termo "lúdico" se refere a divertimento ou jogo.

Atividades lúdicas estão inseridas no contexto educacional há anos, porém, seu maior foco é com as séries iniciais, ou seja, na aplicação com as crianças. Contudo, com a ampliação da produção de jogos on line para aplicação na área da saúde, denominados como jogos sérios ou serious games esta atividade vem ganhando espaço também em cursos superiores. Porém, Pires et al. (2017, p. 02) evidenciam a "limitação teóricoconceitual adotada nas produções dos jogos em distintos cenários de aprendizagem da saúde e da enfermagem" afirmam que isso "dificulta investigações e práticas discursivas".

Apesar dessa limitação, há quem afirme que os elementos visuais associados a textos proporcionam maior facilidade de compreensão. Por meio da PROINFO nota-se que o Ministério da Educação (MEC) corrobora com a inserção da tecnologia à educação, desde 1.997, sendo que em 2007, por meio do Decreto de $\mathrm{n}^{\circ} \mathbf{6 . 7 0 0}$, o objetivo do programa passou a promoção do uso de TICS na rede pública de ensino.

Em 2.011 o MEC disponibilizou o Edital de convocação para o processo de inscrição e avaliação de coleções didáticas para o programa nacional do livro didático (PNLD) o qual evidencia a importância da inserção de jogos eletrônicos, definido como "uma categoria de software de entretenimento cujo objetivo da interação envolve completar uma tarefa, vencer um desafio, obter a maior pontuação, derrotar um adversário (real ou imaginário)" e simuladores, descritos como "softwares ou gráficos interativos que demonstra um processo ou mecanismo que permite ao usuário observá-lo ou interagir com ele de maneira análoga ao processo ou mecanismo simulado, obtendo resultados realistas" no processo de ensino-aprendizagem (SILVA, 2014 apud BRASIL, 2013, p.77-78; BRASIL, s/d).

Por meio do estudo realizado por Shaw e Rocha (2014) percebe-se que o formato do jogo é de suma importância para que o processo obtenha sucesso. No estudo mencionado os entrevistados criticam muito a linguagem utilizada, bem como o nível de dificuldade acentuado tornou-se desestimulante aos discentes. Contudo, mesmo com o insucesso na aplicação do jogo, os pesquisadores puderam perceber, por meio dos resultados, as dificuldades que os alunos tinham no conteúdo abordado.

Ramos (2012) realizou um estudo para verificar a influência dos jogos para a formação moral de adolescentes e percebeu que esta ferramenta "contribui com os processos de subjetivação", mas que não pode ser considerada como determinante nesse processo. O mesmo ocorre na utilização de games na educação, ou seja, um jogo pode ser considerado como um elemento importante e positivo no processo de ensino- 
aprendizagem, mas, obviamente, não pode ser a única ferramenta utilizada nesse processo.

Já Lima (2015, p. 32) menciona a necessidade de rever os processos durante a implantação de novas ferramentas pedagógicas, evidencia que o sucesso da inserção de um game no processo de ensino-aprendizagem está justamente em não "insistir em não rever a forma de estruturar o game, permanecendo na ideia de que somente se avance ao alcançar a resposta certa" afirma ainda que isso "pode levar o aluno a desistir do jogo ou comprometer, em parte, o entusiasmo dos alunos quando forem utilizar o game por não conseguirem ou levarem muito tempo para passar as fases propostas". Por fim, o estudo desse autor, apontou que a inserção do game trouxe inovação ao processo de ensino aprendizagem e que isto despertou o interesse dos alunos, resultando em uma atividade vantajosa.

Audi (2014, p. 779) considera que para se obter êxito na implementação de um game é preciso que ofereça ao jogador um tutorial. Para o autor essa etapa mostra-se eficiente para "sensação de imersão no mundo ficcional", outra questão exposta pelo autor é com relação a interface, citada também pelos autores supracitados,

"Jogos eletrônicos demandam uma multiplicidade de habilidades em função da mistura de linguagens e estímulos. Toda esta complexidade, no entanto, precisa desaparecer, do contrário, o usuário passaria mais tempo preocupando-se com a interface do que jogando" (AUDI, 2014, p. 783).

\section{RESULTADOS E DISCUSSÃO}

Por meio dos resultados obtidos foi possível perceber que a atividade não despertou o interesse dos alunos da forma como deveria, pois, entre os 332 alunos vinculados à unidade curricular de Gestão em Recursos Humanos apenas 25\% acessaram a atividade, sendo que entre esses apenas $24 \%$ a concluiu (gráfico 1 ).

Considerando o número de jogos concluídos (21) ao número total de alunos na oferta (332) percebe-se que apenas $6 \%$ dos alunos realizaram a atividade integralmente (gráfico 1). 
Gráfico 1: İndice de acesso e conclusão do game

Número de jogos concluidos considerando todos os alunos vinculados à disciplina

Número de jogos concluídos (considerando apenas aqueles que acessaram)

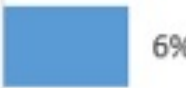
$6 \%$

Número de acessos ao jogo

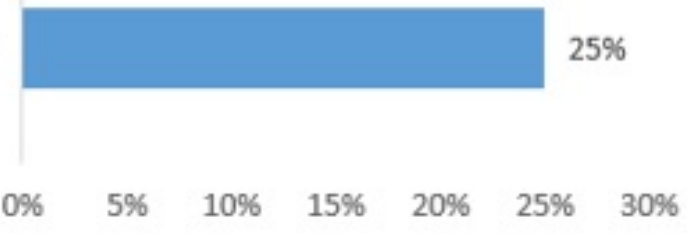

Fonte: Os autores, 2018

Este baixo índice de realização e conclusão do game pode estar relacionado com a faixa etária dos alunos, pois o universo do lúdico, o qual os games estão inseridos, atinge mais os jovens e o curso EAD tem um perfil predominantemente de pessoas na fase adulta, fase que que encontra-se ainda em processo de inserção neste universo (ABED, 2016); ou mesmo com a interface do jogo, pois, como expõe Pires et al (2017) disso depende a aceitação dos produtos, todas as etapas de desenvolvimento dos jogos se concentram na experiência sensorial dos/as usuários/as (os que se utilizam de computador), ou seja, se o jogo não estiver atrativo o suficiente para prender a atenção do aluno ele não irá realizá-lo por completo.

\section{CONCLUSÃO}

A inserção de novas atividades pedagógicas que envolvam a tecnologia é promissora e estimulada pelos órgãos competentes, principalmente, para os alunos da Educação a distância, pois, a interatividade traz o aluno para perto da instituição e ajuda no processo de vínculo professor-aluno, além de, possibilitar a aplicação de casos que aproximem o discente da realidade profissional.

De acordo com os resultados levantados nesse estudo percebe-se que os alunos do curso EAD de CST em Gestão em Saúde Pública vinculados a disciplina de Gestão em recursos humanos, não se sentiram suficientemente atraídos a realizar a atividade proposta, pois entre os 332 alunos apenas $25 \%$ acessou o game e entre esses apenas $24 \%$ o concluiu (índice que corresponde apenas a $6 \%$ dos alunos da oferta). 
Esse estudo, porém, limitou a investigar o interesse dos alunos por novas propostas lúdicas de atividades, por isso, não foi levantado o motivo deste baixo índice de acesso, o que se torna uma proposta para estudos futuros.

\section{REFERENCIAS}

ALCANTARA, C.S.; BEZERRA, J.A.B. O LÚDICO, A ESCOLA E A SAÚDE: A EDUCAÇÃO ALIMENTAR NO GIBI. Trab. Educ. Saúde, Rio de Janeiro, v. 14 n. 3, p. 889-904, set. /dez. 2016.

AUDI.G. Letramento em games: o aprendizado na utilização de novos meios. Linguagem \& Ensino, Pelotas, v.17, n.3, p.778 777-796, set./dez. 2014.

AURÉLIO. Dicionário Aurélio de Português. 2016. Disponível em:< https://dicionariodoaurelio.com/ludico >.Acesso em 19 mar. 2018.

BRASIL. Ministério da Educação (MEC). Fundo nacional de desenvolvimento da educação (FNDE) e Secretaria de educação básica (SEB). EDITAL DE CONVOCAÇÃO 06/2011 -Edital de convocação para o processo de inscrição e avaliação de coleções didáticas para o programa nacional do livro didático PNLD 2014. Disponível em:< http://www.fnde.gov.br/centrais-de-conteudos/publicacoes/category/165-editais?downloa d=8046:pnld-2014-edital-consolidado-3-alteracao > Acesso em 19 mar. 2014.

BRASIL. Ministério da Educação. Fundo Nacional de Desenvolvimento da Educação. Prolnfo. $\quad[\mathrm{s} / \mathrm{d}]$. $\quad$ Disponível em:< http://www.fnde.gov.br/programas/proinfo/sobre-o-plano-ou-programa/sobre-o-proinfo >.Acesso em 19 mar. 2018.

CHRISTO, D. et al. O uso de tecnologias da informação e comunicação para o acompanhamento dos alunos de pós-graduação ead. In: Anais - 22ํㅡ CIAED Congresso Internacional de Educação a Distância, Águas de Lindóia, SP, 2016. Disponível em:< http://www.abed.org.br/congresso2016/trabalhos/94.pdf >.Acesso em 19 mar. 2018.

CRUZ JUNIOR, G. Vivendo o jogo ou jogando a vida? Notas sobre jogos (digitais) e educação em meio à cultura ludificada. Rev Bras Ciênc Esporte, v.39, n.3, p. 226-232, 2017. 
FERREIRA, C.R.et al. Tecnologia no apoio e qualificação de atividades escolares com alunos do $4^{\circ}$ ano do ensino fundamental. In: Revista Tecnologia Educacional, Rio de Janeiro, RJ, n. 218 p. 68 a 74, jul. /set. 2017.

LIMA, R.R.S. Uso de objeto de aprendizagem na forma de game como uma alternativa viável a listas de exercícios e fixação de conteúdo. [ Trabalho de conclusão de curso] Licenciatura em Matemática. Pontifícia Universidade Católica do Rio Grande do Sul, Porto Alegre 2015.

PIRES, M.R.G.M. et al. Recriar-se lúdico no desenvolvimento de jogos na saúde: referências teórico-metodológicas à produção de subjetividades críticas. Texto Contexto Enferm, v.26, n.4, 2017.

RAMOS, D.K. Jogos eletrônicos e juízo moral: um estudo com adolescentes do ensino médio. Psicologia: teoria e prática, v. 14, n. 1, p. 97-112, 2012.

SCARIN, A.C.C.F. Relato de Prática Profissional. O lúdico e a ampliação de perspectivas em atividades pedagógicas. Psicologia Escolar e Educacional, SP. v. 20, n. 3, p. 633-635, set. /dez.2016.

SHAW, G.L.; ROCHA, J.B.T. Uso de games no ensino superior: Caso do Code Fred. Revista OPARA, v. 6, n.2 - Edição Especial - Agosto/2015.

SILVA, E.M.O. OS GAMES E A APRENDIZAGEM DE LÍNGUA INGLESA SOB A ÓTICA DO CONECTIVISMO. 2014. [Mestrado]. Estudos Linguísticos, na linha de pesquisa Linguagens, culturas e identidades: ensino e aprendizagem. Universidade Federal do Paraná, Curitiba, 2014. Disponível em:< https://acervodigital.ufpr.br/handle/1884/42733 >.Acesso em 19 mar. 2018.

STEINBERG, S. Kindercultura: a construção da infância pelas grandes corporações. In: SILVA, L. H.; AZEVEDO, J.C.; SANTOS, E. (orgs.). Identidade social econstrução do conhecimento. Porto Alegre: SMED/RS, 1997. p. 99-145. 